\title{
TERMODYNAMIKA PROCESU SPALANIA MIESZANEK WZBOGACONYCH W TLEN
}

\begin{abstract}
W artykule zostały poruszone aspekty zastosowania mieszanki wzbogaconej w tlen w silnikach spalinowych. Omówiono problemy wynikające z takiego sposobu prowadzenia procesu spalania oraz spróbowano rozwiązać jedną z największych przeszkód we wprowadzeniu wspomnianej techniki do powszechnego zastosowania. Podano sposób kontrolowania temperatury podczas spalania w atmosferze tlenowej oraz wyjaśniono przyczyny obniżenia teoretycznej temperatury spalania dla omawianego przypadku spalania tlenowego.
\end{abstract}

Słowa kluczowe: spalanie tlenowe, adiabatyczna temperatura spalania, kontrolowanie procesu spalania

\section{Wstęp}

Wprowadzanie coraz nowszych przepisów normujących ilość szkodliwych składników spalin emitowanych przez bloki energetyczne skutkowało poszukiwaniem i stosowaniem zaawansowanych technologii redukujących te emisje. Zaistniałe zmiany w energetyce zawodowej pozwoliły dostrzec znaczący udział w emisjach pochodzących z przemysłu motoryzacyjnego (rys. 1.). Dostrzeżenie wysokich wartości emisji powodowanych przez pojazdy samochodowe skutkowało podjęciem wielu działań zmierzających do ich redukcji [6]. Fakt ten powoduje, że obok energetyki zawodowej również przemysł motoryzacyjny jest zmuszony do działań zmierzających do opracowania nowych, niskoemisyjnych technik spalania. Jedną z proponowanych technik jest spalanie z wykorzystaniem powietrza wzbogaconego w tlen. W ostatnim dziesięcioleciu liczba badań nad takim rozwiązaniem dla bloków energetycznych znacząco wzrosła [8]. Mimo że pierwsze próby zastosowania powietrza modyfikowanego w silnikach spalinowych miały miejsce ponad 50 lat temu [9], to jednak do dnia dzisiejszego nie znalazły one praktycznego zastosowania.

\footnotetext{
1 Autor do korespondencji/corresponding author: Artur Nemś, Politechnika Wrocławska, ul. Wybrzeże Wyspiańskiego 27, 50-370 Wrocław, tel.: (71) 3203673, e-mail: artur.nems@pwr.edu.pl.

${ }^{2}$ Michał Pomorski, Politechnika Wrocławska, e-mail: michal.pomorski@pwr.edu.pl.
} 


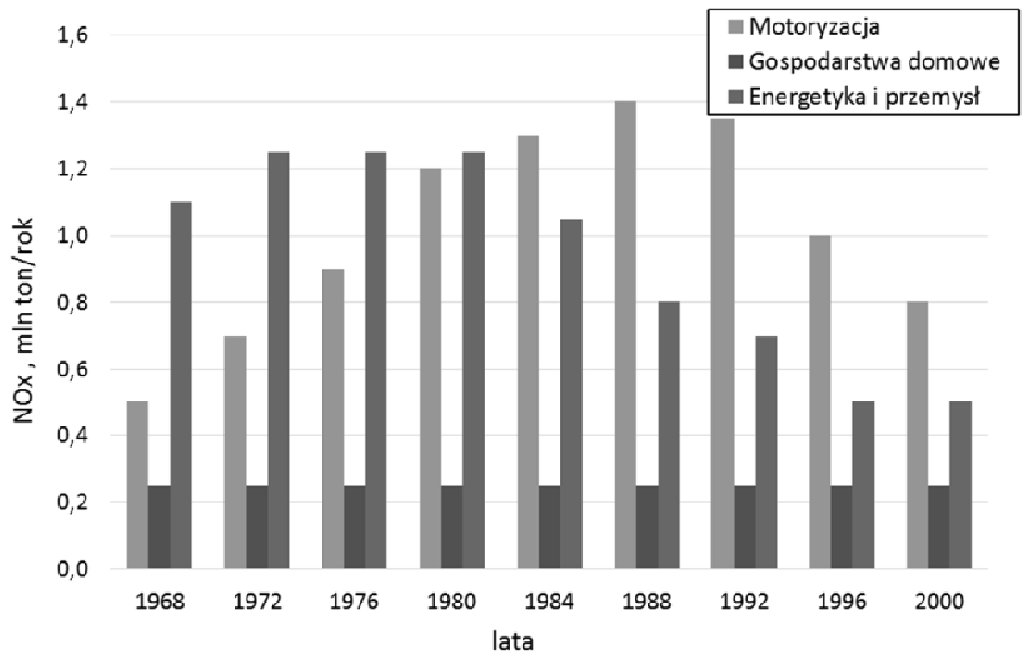

Rys. 1. Emisja tlenków azotu w Niemczech na przestrzeni lat (na podstawie [3])

Fig. 1. Emission of nitrogen oxides in Germany throughout the years (on the basis of [3])

Powodem są głównie problemy techniczne wynikające z kontrolowania temperatury spalania. Rozwiązanie tego problemu może się okazać niezbędne w celu wprowadzenia techniki tlenowej w silnikach cieplnych wewnętrznego spalania.

\section{Kontrolowanie procesu spalania mieszanek wzbogaconych $w$ tlen}

Opisane w literaturze $[2,5,11]$ badania stosowania powietrza wzbogaconego w tlen w silnikach z zapłonem iskrowym (ZI) były prowadzone ze współczynnikiem nadmiaru powietrza bliskim jedności. Jest to powszechnie znany sposób pozwalający na zwiększenie ilości spalanego paliwa wskutek zwiększenia stężenia tlenu $\mathrm{w}$ doprowadzanym do silnika powietrzu. Tak prowadzony proces spalania skutkuje szybko wzrastającą, wraz z rosnącym stężeniem tlenu, temperaturą spalania (rys. 2.). W ten sposób realizowany proces wiąże się z technicznymi ograniczeniami. Nieopanowanie dopuszczalnej temperatury spalania (ok. $3000 \mathrm{~K}$ ) w dostatecznie krótkim czasie powoduje przeciążenia cieplne i mechaniczne, prowadzące do uszkodzenia silnika [10]. Dlatego maksymalne stężenie tlenu doprowadzanego do silnika w sposób ciągły nie może przekraczać wartości dwudziestu kilku procent. Powoduje to znaczne ograniczenia w stosowaniu powietrza wzbogaconego $\mathrm{w}$ tlen. 


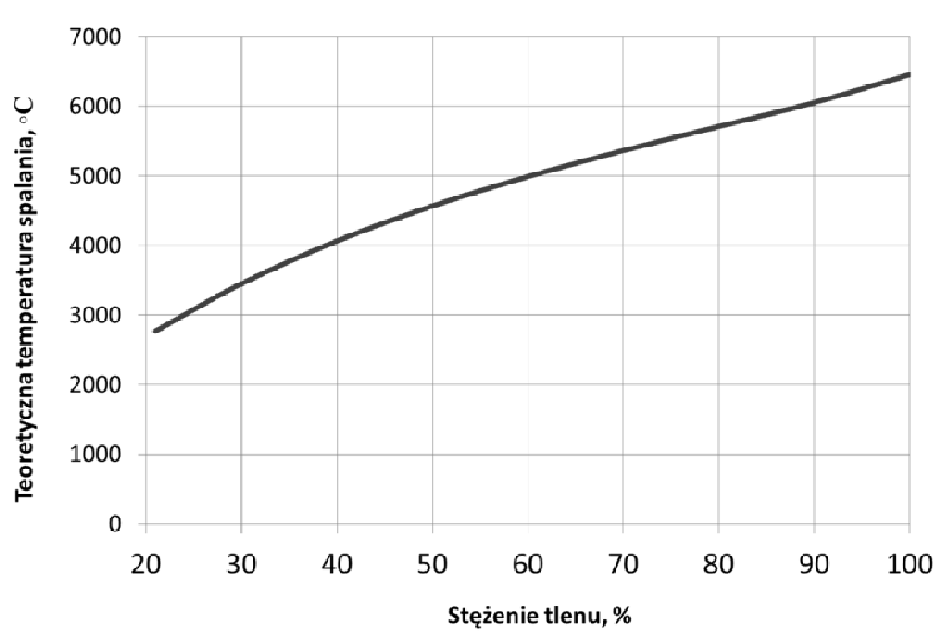

Rys. 2. Teoretyczna temperatura spalania w funkcji stężenia tlenu

Fig. 2. The theoretical combustion temperature as a function of the oxygen concentration

\section{Algorytm obliczeń procesu spalania dla niecałkowitego wykorzystania tlenu}

Jeśli zostanie rozpatrzony przypadek, w którym pojawi się tlen w spalinach przy założonym teoretycznie współczynniku nadmiaru powietrza $\lambda=1$, to konieczne będzie zmodyfikowanie znanych równań i określenie ilości tlenu biorącej i niebiorącej (w sposób bezpośredni) udziału w procesie spalania. Takie rozważania są istotne dla przypadku spalania w atmosferze tlenowej, w której (w uproszczeniu) azot jest zastępowany tlenem. W celu pokazania wpływu zamiany azotu na tlen, przy opisanym wcześniej warunku, przyjęto następujące założenia:

- spalane jest paliwo ciekłe (benzyna o składzie masowym $85 \%$ węgla i $15 \%$ wodoru),

- spalanie jest całkowite i zupełne,

- spalanie odbywa się w silniku spalinowym o zapłonie iskrowym,

- parametry zasysanego powietrza: $t_{o t}=20^{\circ} \mathrm{C}, p_{o t}=1 \mathrm{bar}$,

- objętość skokowa silnika ZI: $V_{s}=1 \mathrm{dm}^{3}$,

- stopień kompresji w silniku: $\varepsilon=8$,

- doprowadzane do silnika powietrze jest mieszaniną tlenu i azotu (gazy półdoskonałe), którego udziały molowe spełniają zależność: $z_{\mathrm{O}_{2}}+z_{\mathrm{N}_{2}}=1$. 
Zakładając, że tylko część tlenu bierze bezpośredni udział w procesie spalania, można zapisać:

- udział molowy zużywanego tlenu w procesie spalania to $z_{\mathrm{O}_{2}^{1}}$,

- udział molowy niespalanego (niewykorzystywanego bezpośrednio w reakcji spalania) tlenu to $z_{\mathrm{O}_{2}^{2}}$, czyli: $z_{\mathrm{O}_{2}^{1}}+z_{\mathrm{O}_{2}^{2}}=z_{\mathrm{O}_{2}}$.

Podczas bilansowania energii w rozpatrywanym przypadku dla adiabatycznego spalania całkowitego i zupełnego przy stałej objętości, bez wykonania pracy, wiadome jest, że suma energii wewnętrznej substratów i wartości opałowej paliwa jest równa energii wewnętrznej produktów, co można przedstawić równaniem:

$$
\begin{aligned}
& W_{u}+c_{v_{p a l}}\left(T_{p a l}-T_{o t}\right)+\lambda L_{t k g} c_{v_{p o w}} \mid T_{\text {pow }}\left(T_{\text {pow }}-T_{o t}\right)= \\
& =\left(1+\lambda L_{t k g}\right) c_{v_{s p}} \mid T_{t}\left(T_{t}-T_{o t}\right)
\end{aligned}
$$

gdzie: $W_{u}$ - wartość opałowa paliwa, $c_{v_{p a l}}$ - ciepło właściwe paliwa, $L_{t k g}-$ masowe zapotrzebowanie na powietrze do spalania, $c_{v_{p o w}}$ - ciepło właściwe powietrza, $c_{v_{s p}}$ - ciepło właściwe spalin, $T_{t}, T_{p a l}, T_{o t}, T_{p o w}$ - odpowiednio temperatura teoretyczna, paliwa, otoczenia, powietrza do spalania.

Po przekształceniu teoretyczną temperaturę spalania przy stałej objętości opisuje następujące równanie:

$$
T_{t}=\frac{W_{u}+c_{v_{p a l}}\left(T_{p a l}-T_{o t}\right)+\lambda L_{t k g} c_{v_{p o w}} \mid \begin{array}{l}
T_{p o w} \\
T_{o t}
\end{array}\left(T_{p o w}-T_{o t}\right)}{\left(1+\lambda L_{t k g}\right) c_{v_{s p}} \mid T_{t o t}}+T_{o t}
$$

Ze względu na wzajemną relację temperatury i ciepła właściwego, teoretyczną temperaturę spalania wraz z pojemnością cieplną spalin wyznaczono iteracyjnie. Tak przeprowadzone obliczenia pozwoliły pokazać, jak wpływa wyższe stężenie tlenu w zasysanym przez silnik powietrzu na teoretyczną temperaturę spalania, w przypadku gdy spalana jest taka sama ilość paliwa jak podczas pracy silnika w powietrzu atmosferycznym (rys. 3.). Można zauważyć, że w przedstawionym przypadku zmniejszeniu ulega teoretyczna temperatura spalania, która w przypadku doprowadzania czystego tlenu sięga 20\%. Obniżenie temperatury spalania jest związane $\mathrm{z}$ większą pojemnością cieplną tlenu niż azotu (rys. 4.). Takie rozwiązanie pozwala stosować powietrze o wysokim stężeniu tlenu, przekraczającym $30 \%$ objętości $[4,7]$. 


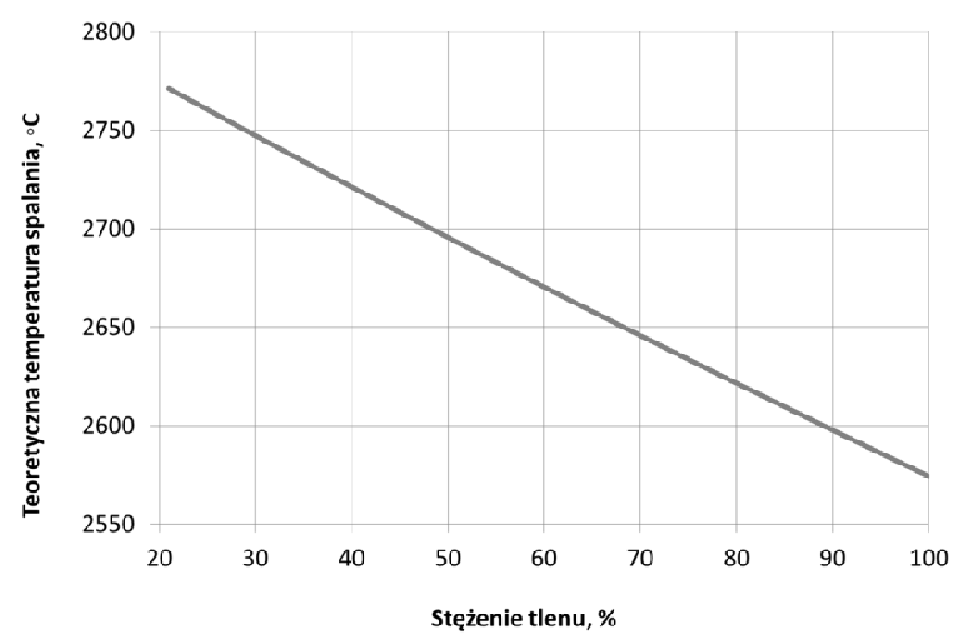

Rys. 3. Teoretyczna temperatura spalania w funkcji stężenia tlenu dla stałej ilości reagującego tlenu wynoszącej $21 \%$

Fig. 3. The theoretical combustion temperature as a function of the oxygen concentration at constant amount of reactive oxygen of $21 \%$

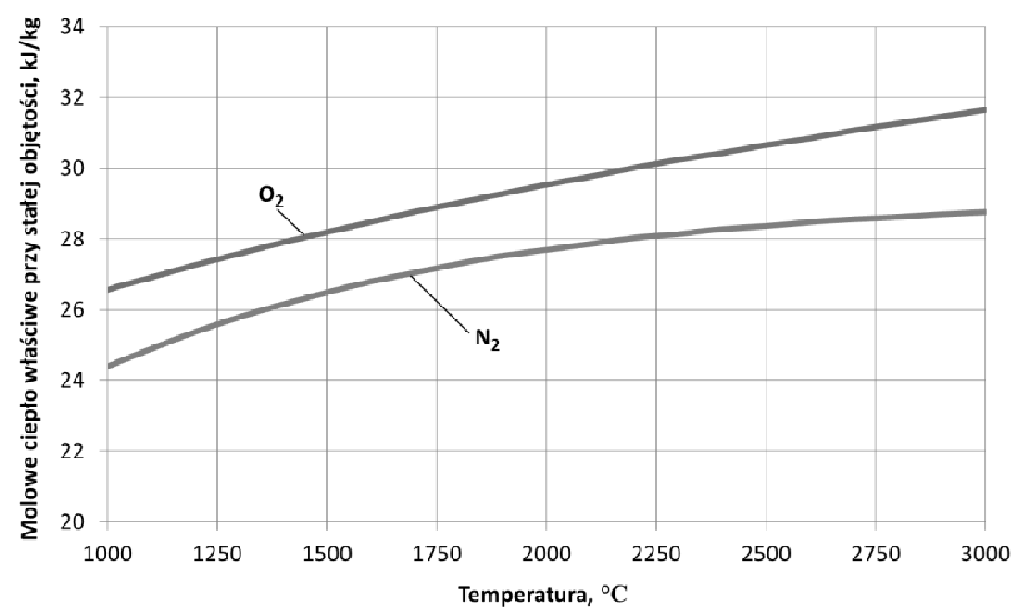

Rys. 4. Molowe ciepło właściwe przy stałej objętości w funkcji temperatury

Fig. 4. The molar heat capacity at constant volume as a function of temperature

Zmiana proporcji tlenu i azotu $\mathrm{w}$ doprowadzanym do silnika powietrzu wpływa na zmianę składu spalin. Ma to wpływ na molową pojemność cieplną spalin (rys. 5.). Strumień wydzielanego ciepła $Q$ w trakcie procesu spalania pozostaje bez zmian ze względu na stałą ilość spalanego paliwa (pomija się wzrost sprawności spowodowany wypaleniem paliwa w środowisku tlenowym). 


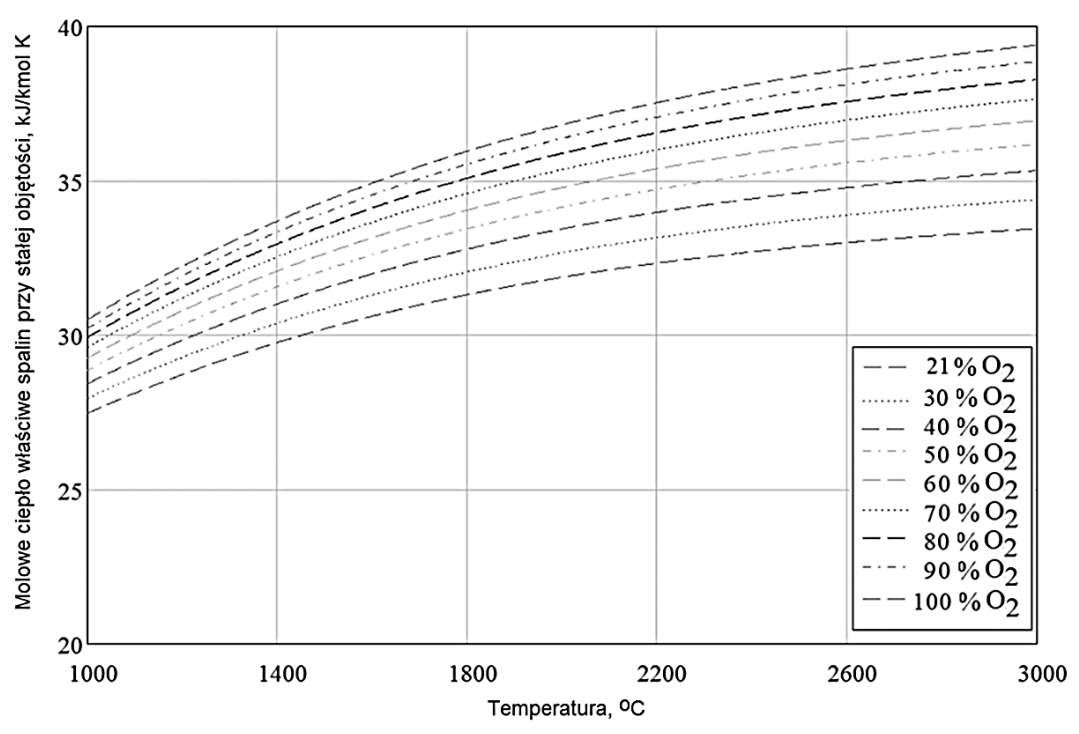

Rys. 5. Molowe ciepło właściwe spalin przy stałej objętości w funkcji temperatury i stałej ilości reagującego tlenu wynoszącej $21 \%$

Fig. 5. Molar specific heat capacity of exhaust gas at a constant volume as a function of temperature at constant amount of reactive oxygen of $21 \%$

Zgodnie z równaniem:

$$
Q=n M c_{v}\left(T_{k}-T_{p}\right)
$$

gdzie: $n$ - liczba moli, $c_{v}$ - ciepło właściwe przy stałej objętości, $T_{k}, T_{p}$ - odpowiednio temperatura końcowa i początkowa,

wraz ze wzrostem molowej pojemności cieplnej spalin i niezmiennej liczby moli substancji znajdującej się w komorze cylindra maleje różnica temperatur. Przy stałej temperaturze początkowej procesu obniżeniu ulega temperatura końcowa [1].

Przedstawiony sposób spalania mieszanek wzbogaconych w tlen, w których tlen nie jest całkowicie wykorzystywany, umożliwia nowy rodzaj kontrolowania procesu spalania. Takie rozwiązanie pozwala na doprowadzanie, w sposób ciągły, powietrza o zwiększonym stężeniu tlenu. Metoda ta umożliwia również utrzymanie stałej temperatury spalania niezależnie od stężenia tlenu. W tym celu niezbędne jest nieznaczne zwiększanie ilości paliwa wraz z szybko wzrastającym stężeniem tlenu. Zakres możliwych do uzyskania teoretycznych temperatur spalania został przedstawiony na rys. 6 . 


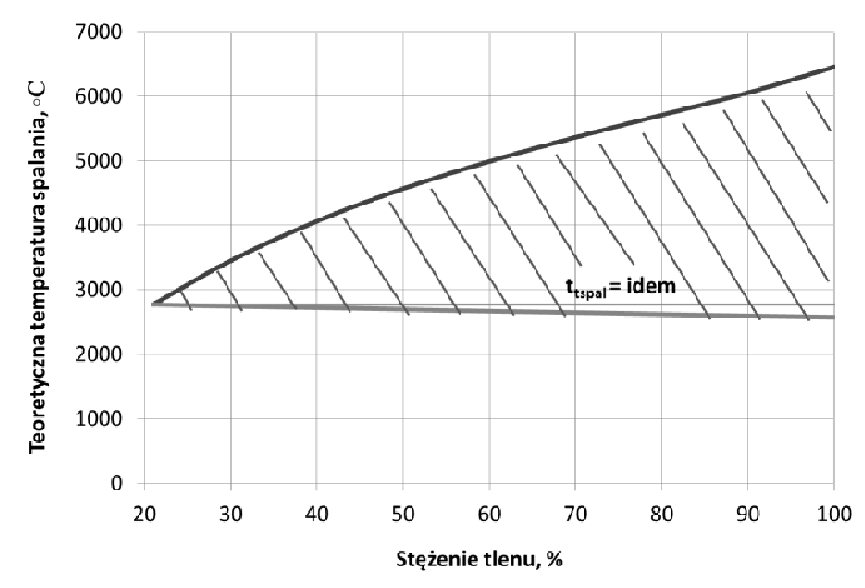

Rys. 6. Zakres możliwych do uzyskania temperatur podczas spalania mieszanek wzbogaconych w tlen

Fig. 6. The range of possible to obtain temperatures during combustion of oxygen-enriched mixtures

\section{Podsumowanie}

Opisany sposób prowadzenia procesu spalania nie jest zabiegiem korzystnym z punktu widzenia ekonomicznego. Może się jednak wiązać z licznymi korzyściami technicznymi i ekologicznymi, np. powodować poprawę efektywności spalania paliwa, pomagając lepiej kontrolować temperaturę spalania, w sposób nieznaczny zwiększyć moc. Środowisko tlenowe powinno również korzystnie wpłynąć na redukcję CO i HC [1] w spalinach, ze względu na rzadsze występowanie stref $\mathrm{z}$ niedomiarem tlenu $\mathrm{w}$ komorze spalania. Ponadto może mieć korzystny wpływ na pracę silnika, gdy występują problemy z przepłukaniem. Takie zjawisko występuje podczas pracy silnika na biegu jałowym. Przy zastosowaniu wyższego stężenia tlenu pozostające w komorze spalania spaliny zawierałyby tlen, który mógłby zostać wykorzystany w kolejnym cyklu.

\section{Literatura}

[1] Błasiak P., Nemś A.: The numerical modelling of thermos-flow processes for a verification of a new conception of oxygen-enriched combustion. Nowe trendy w naukach inżynieryjnych, pod red. M. Kuczery, Creativetime, Kraków 2011, s. $164-172$.

[2] Caton J.A.: Use of a cycle simulation incorporating the second law of thermodynamics: Results for spark-ignition engines using oxygen enriched combustion air, SAE Word Congress Detroit, SAE papers 2005011130, Michigan 2005.

[3] Emisja toksycznych składników spalin w Niemczech na przestrzeni lat, http://www.portal.zssio.pl/index.php?option=com_content\&view=category\&id=39:p rzedmioty-zawodowe\&Itemid=49\&layout=default (dostęp: 19 czerwca 2012 r.). 
[4] Gnutek Z., Nemś A., Pomorski M.: Badania niestechiometrycznego spalania mieszanek wzbogaconych w tlen w silnikach cieplnych o zapłonie iskrowym, XIV Sympozjum Wymiany Ciepła i Masy, SWCIM, Międzyzdroje 2010, s. 217-224.

[5] Maxwell T.T., Jones J.C., Setty V.: The effect of oxygen-enriched air on the performance and emissions of an internal combustion engine, SAE papers 932804 , 1993.

[6] Nemś A.: Niskoemisyjne silniki: elektryczne czy spalinowe?, Energia - Gigawat, nr 8 (dokument elektroniczny), 2012.

[7] Nemś A., Pomorski M.: Nowa koncepcja izochorycznego spalania tlenowego. Rozwój zrównoważony - zarządzanie technologiami, pod red. R. Grądzkiego, J. Gralewskiego i A. Marcinkowskiego, Media Press, Łódź 2010, s. 72-79.

[8] Nowak W. i in.: Prace badawcze w dziedzinie fluidalnego spalania w tlenie, Technologie zeroemisyjne - Spalanie tlenowe, Komitet Problemów Energetyki, 2008, s. 69-87.

[9] Śliwiński K.: Perspektywy zasilania silników ZI mieszanką wzbogaconą w tlen, Czasopismo Techniczne, Wydawn. WPK, 2008, s. 55-65.

[10] Wajand J.A., Wajand J.T.: Tłokowe silniki spalinowe średnio- i szybkoobrotowe, WNT, Warszawa 2005.

[11] Wartinbee W.J.: Effect of Oxygen Enriched Air on Exhaust Emission, SAE papers $710606,1971$.

\title{
THERMODYNAMICS OF COMBUSTION PROCESS OF OXYGEN ENRICHED MIXTURES
}

\begin{abstract}
S u m m a r y
The article presents the use of oxygen-enriched mixture in internal combustion engines. The problems arising from such a method of conducting the combustion process and the attempts to solve one of the biggest obstacles to applying such technique for applications were discussed The ways of controlling the temperature of the combustion in oxygen atmosphere were explained and the reasons for reduction the theoretical flame temperature of discussed case of oxygen combustion were explained.
\end{abstract}

Keywords: oxygen combustion, adiabatic combustion temperature, control of combustion process

DOI: $10.7862 / \mathrm{rm} .2015 .14$

Otrzymano/received:14.09.2014 r.

Zaakceptowano/accepted:20.02.2015 r. 